NASA Technical Memorandum 106576

AIAA-95-364

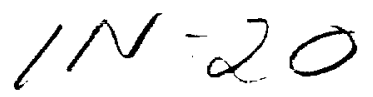

\title{
Direct Drive Options for Electric Propulsion Systems
}

John A. Hamley

Lewis Research Center

Cleveland, Ohio

Prepared for the

30th Intersociety Energy Conversion Engineering Conference cosponsored by ASME, IEEE, AIChE, ANS, ACS, and AIAA Orlando, Florida, July 31-August 4, 1995
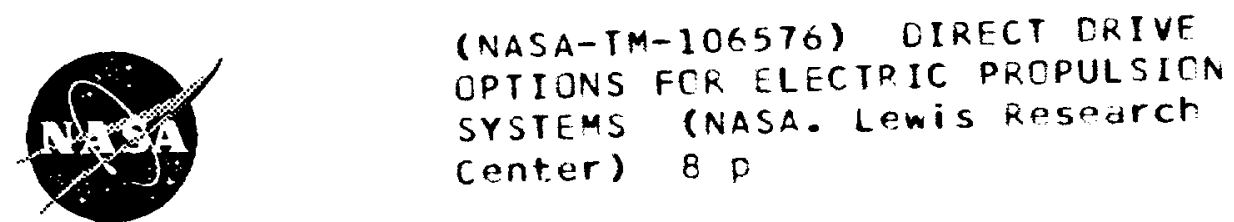

N95-27861

Unclas

National Aeronautics and

Space Administration 



\title{
DIRECT DRIVE OPTIONS FOR ELECTRIC PROPULSION SYSTEMS
}

\author{
John A. Hamley \\ National Aeronautics and Space Administration \\ Lewis Research Center \\ 21000 Brookpark Road \\ Cleveland, Ohio 44135 \\ (216) $-433-4000$
}

\begin{abstract}
Power processing units (PPUs) in an electric propulsion system provide many challenging integration issues. The PPU must provide power to the electric thruster while maintaining compatibility with all of the spacecraft power and data systems. Inefficiencies in the power processor produce heat, which must be radiated to the environment in order to ensure reliable operation. Although PPU efficiencies are generally greater than 0.9 , heat loads are often substantial. This heat must be rejected by thermal control systems which generally have specific masses of $15-30 \mathrm{~kg} / \mathrm{kW}$. PPUs also represent a large fraction of the electric propulsion system dry mass. Simplification or elimination of power processing in a propulsion system would reduce the electric propulsion system specific mass and improve the overall reliability and performance. A direct drive system would eliminate all or some of the power supplies required to operate a thruster by directly connecting the various thruster loads to the solar array. The development of concentrator solar arrays has enabled power bus voltages in excess of $300 \mathrm{~V}$ which is high enough for direct drive applications for Hall thrusters such as the Stationary Plasma Thruster (SPT). The option of solar array direct drive for SPTs is explored to provide a comparison between conventional and direct drive system mass.
\end{abstract}

\section{INTRODUCTION}

Primary or auxiliary electric propulsion systems provide many potential benefits to the spacecraft manager when compared to chemical propulsion systems. The high specific impulse provided by electric thrusters substantially reduces the amount of propellant required to achieve a given mission. This mass savings can be leveraged in many ways including reduction of spacecraft mass, reduced launch vehicle requirements, increased on-orbit lifetime, or increased payload.
A conventional electric propulsion system is shown in Figure 1. The main components include the electric power source, power processing unit (PPU), thruster, and propellant system. Of these components, the PPU can be considered as the most impactive to the spacecraft in terms of integration complexity The PPU conditions the power supplied by the power source and matches it to the load requirements of the thruster. provides a command and telemetry interface to the electric propulsion system, and in some cases, controls the propellant management system. To perform these functions, the PPU must connect to the power, command and data, and thermal management systems.

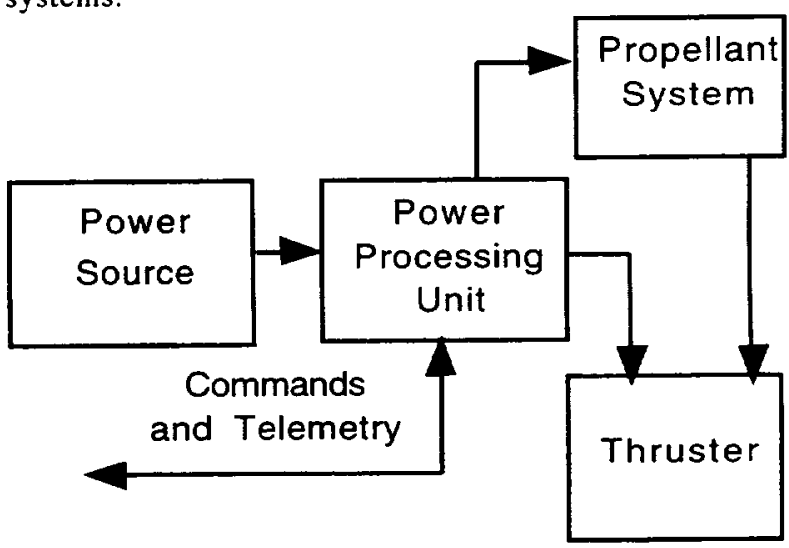

Figure 1. Electric Propulsion system block diagram.

PPUs have varying levels of complexity, specific mass, and power conversion efficiencies. These characteristics depend on the thruster, the propulsion system architecture, and the characteristics of the input power source. The simplest PPUs to date are single converter units used to drive electrothermal arcjets and resistojets. Electrostatic rockets such as Hall effect 
and gridded ion thrusters require several converters for steady state operation. To minimize spacecraft integration issues, PPU designers attempt to find an optimal compromise between efficiency, mass, and volume. Each of these considerations must be weighed in the optimization process. Overall efficiency is a primary concern due to the $15 \cdot 30 \mathrm{~kg} / \mathrm{kW}$ specific mass of thermal rejection systems as reported by Byers (1980).

While state of the art PPUs perform their functions quite well, it is anticipated that future mission performance demands will require even lighter, more efficient propulsion systems. NASA's long term goal is to develop propulsion systems with a specific mass of less than $10 \mathrm{~kg} / \mathrm{kW}$, and this will require direct drive. Direct drive systems eliminate or simplify the PPU with solar arrays configured to connect directly, or through an EMI filter, to a thruster. A simplified direct drive system is shown in Figure 2. In this concept, the thruster is directly connected to the solar array through an EMI filter, with a Controller/Interface Unit (CIU) providing the command/telemetry interface and flow system control. This CIU consists of a few circuit boards and valve drivers and would consume only a few watts of power. This concept eliminates the PPU and substantially reduces the load on the spacecraft thermal system.

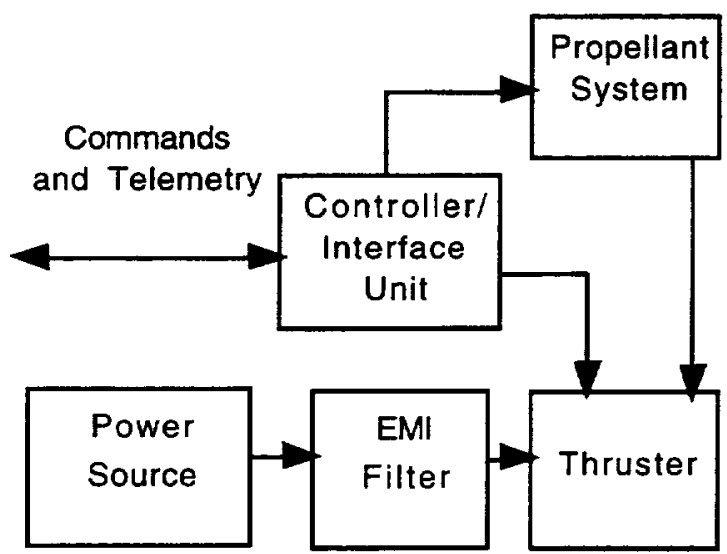

Figure 2. Direct drive electric propulsion system.

This paper explores a potential direct drive scheme with the family of electrostatic Hall thrusters that includes the Stationary Plasma Thruster (SPT) and the Thruster with Anode Layer (TAL). The focus is on integration considerations that must be addressed with or without a PPU, and the overall masses of systems with and without a PPU are presented.

\section{BACKGROUND}

Regardless of the type of electric thruster load being driven, power supply output characteristics can generally be represented by the V-I curve of Figure 3. In the case of constant current output supplies, the output voltage is practically constant until the load impedance is such that the ratio of the output voltage over the load impedance is greater than or equal to the current regulator setpoint. When this occurs, output voltage is reduced to maintain constant output current. The open circuit or light load voltage depends on the input voltage to the power supply and its topology.

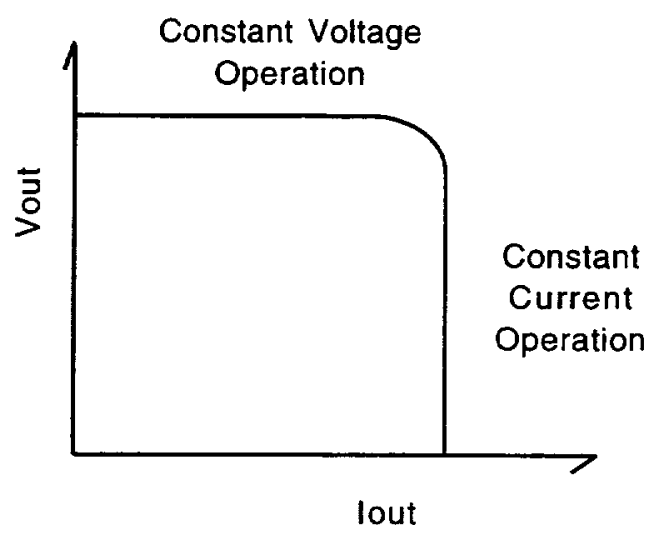

Figure 3. Simplified PPU output characteristic.

Constant output voltage power supplies, such as those used on SPTs, maintain a constant output voltage up to a current limit. The current limiter protects the power supply from load faults or excessive power output. In the current limiter mode, these power supplies operate identically to current sources. In any case, these output characteristics appear very similar to the solar array output, shown scaled from an array described by Gooder (1976), in Figure 4. Note that the output voltage remains relatively constant up to a current limit, which is set by the type and number of cells in the array. The peak output power of the array is realized when the array is loaded near the constant current output region. Output power is reduced in the constant voltage or current regions. Given the similarity of thruster requirements and array characteristics, a case for the implementation of a direct drive system is apparent.

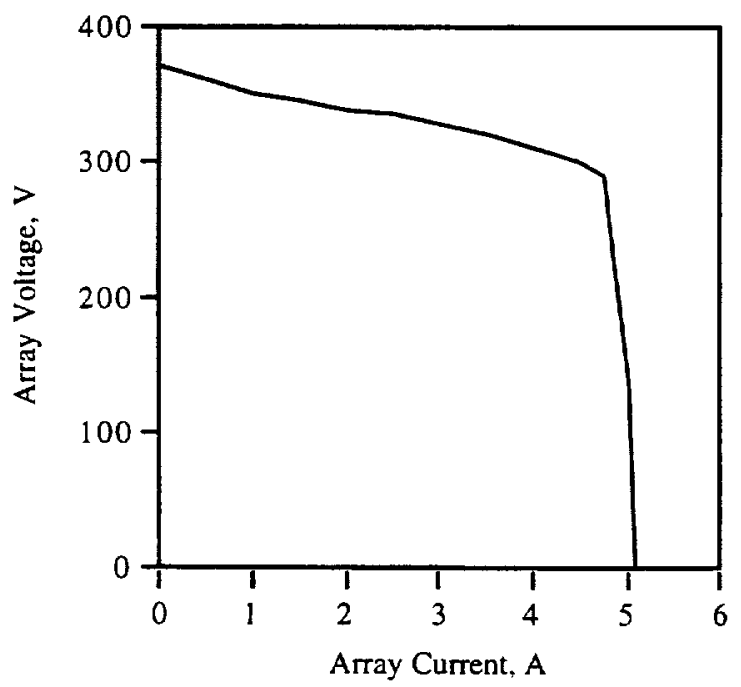

Figure 4. Solar array output characteristic. 


\section{GENERAL REQUIREMENTS AND ASSUMPTIONS}

\section{Power Availability}

The availability of power must be considered in a direct drive scheme. A direct connection to the solar array places constraints on the power available to the electric propulsion and other spacecraft systems. In the case of communications satellites, which have high constant power demand, surplus power for propulsion may not be available. For this reason power for the propulsion system may normally be derived from the spacecraft batteries. Further, it will be shown that for a direct drive implementation with Hall thrusters, the nominal solar array voltage must be $300 \mathrm{~V}$, which may adversely impact the other satellite electronics normally connected to a power system of lesser voltage capability. This problem may be solved with a voltage regulation scheme that arranges strings of cells in series/parallel configurations to achieve the desired array output voltage. This technique has been demonstrated by Gooder (1976) to provide voltage regulation at efficiencies approaching 0.99 . For the purposes of this discussion, it will be assumed that a $300 \mathrm{~V}$ solar array is available.

\section{EMI compatibility}

In all electric propulsion systems power must be derived from the spacecraft bus with little or no impact to the other spacecraft systems. Stringent EMI specifications, such as MIL-STD-461, are used to ensure minimal interference with other spacecraft systems. PPUs therefore contain low pass filters to maintain compatibility with the spacecraft power bus. Elimination of the PPU and its filters, by directly coupling an electric thruster to the power bus, could potentially couple noise generated by the thruster onto the bus. Therefore, an EMI and output filter stage of a conventional PPU may still be required to facilitate operation of the thruster. This mass will be accounted for in the system comparison

\section{Thruster}

As noted, the Hall thruster will be considered as a near term candidate for integration into a direct drive system. These thrusters generally require one high power constant voltage power supply and one low power current source for steady state operation. Thorough descriptions of PPU requirements for the SPT-100 were described by Fischer, et al. (1993) and Hamley, et al. (1993). Two low power supplies are also utilized for the ignition procedure. A simplified diagram of an SPT thruster and its power supply connections are shown in Figure 5. The cathode heater power supply provides power to pre-heat the cathode prior to starting the thruster. The ignitor supply provides a high voltage pulse to the ignitor electrode to initiate the discharge between the anode and the cathode. Both of these power supplies are turned off after the thruster has started.

The plasma discharge is sustained by the discharge power supply, which simultaneously provides the acceleration potential. Flow rate to the thruster is controlled by a thermally controlled orifice, energized by the thermal throttle power supply. Power dissipation is typically less than $100 \mathrm{~W}$ for the heater, thermal throttle, and ignitor supplies. The discharge power supply operates at a nominal $300 \mathrm{VDC}$ at $4.5 \mathrm{~A}$ for the SPT- 100 .

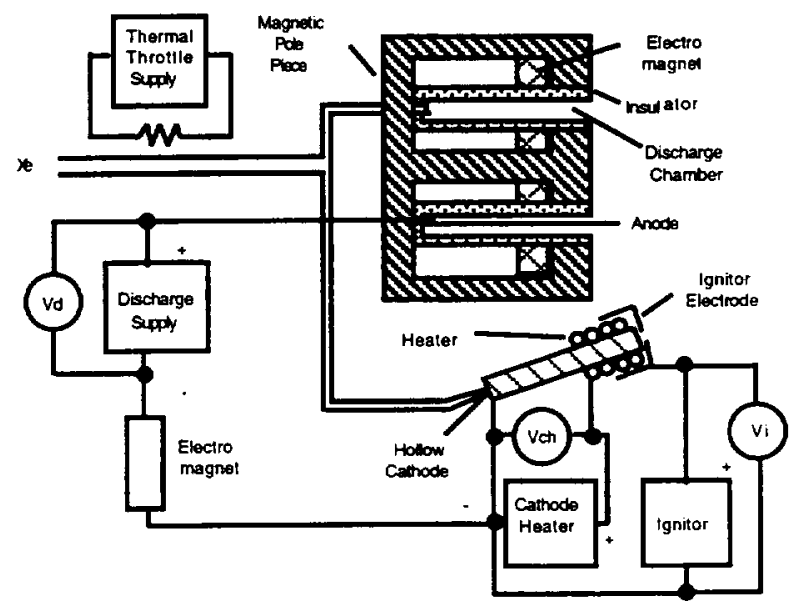

Figure 5. SPT thruster with power supply connections

SPT thruster discharges behave essentially as constant current loads at the nominal operating voltage of $300 \mathrm{~V} \pm 100 \mathrm{~V}$. Discharge current is directly proportional to the flow rate into the anode chamber of the thruster, as described by Bober (1991). Flow to the thruster is controlled by a closed loop which adjusts the temperature of the thermal throttle to achieve the desired discharge current. With a direct drive configuration. the flow rate to the thruster can be adjusted to utilize the maximum power from the solar array. A similar technique for peak power tracking was demonstrated by both Gruber (1977) and Gooder (1977) with gridded ion thrusters using mercury propellant.

Concentrator arrays, now under development, will be capable of $300 \mathrm{~V}$ nominal voltages in the near term without deleterious arcing due to plasma interactions in the LEO environment, as reported by Guidice, et al. (1995). The auxiliary power supplies, which are used only for the ignition of the discharge, are low power units which can be fabricated in small packages. However, the most compelling argument may be the load characteristics of the discharge and the ability of the thruster to operate at off-nominal discharge voltages. This greatly mitigates the need for voltage regulation.

The elimination of the regulated discharge power supply is not without penalty. Thruster performance data compiled by Brophy, et al. (1992) and Sankovic, et al. (1993), indicate that thruster performance varies when operated at off-nominal conditions as shown in Figure 6. Further, since the accelerating potential will vary with array voltage, the thrust and specific impulse will be variable, complicating mission planning and analysis. 


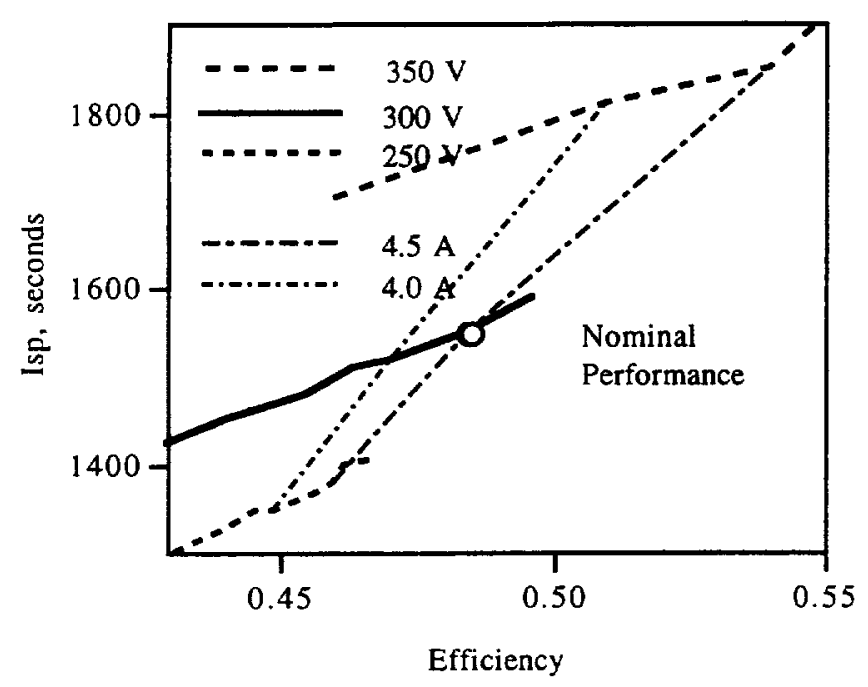

Figure 6. SPT-100 Performance at nominal $300 \mathrm{~V}, 4.5 \mathrm{~A}$ operating point, and with varying acceleration potential and discharge current.

\section{Solar Array}

A linear concentrator solar array was chosen for this system comparison. Using GaAs technology, near-term array specific masses of $80-100 \mathrm{~W} / \mathrm{kg}$ have been predicted by Piszczor, et al. (1994). It is assumed that the array can be configured for the required $300 \mathrm{~V}$ output voltage and this mass would be the same for an array of lower voltage which would be used to drive a power processor. The solar arrays were sized with appropriate power to drive the thruster at $1.35 \mathrm{~kW}$, accounting for PPU efficiency and a $10 \%$ power degradation at end of life (EOL).

\section{Power Processor}

For the standard system, the power processor selected is a flight unit designed specifically for the SPT-100. This PPU, described by Day (1995), has a mass of $8.25 \mathrm{~kg}$ and an efficiency of 0.92 at an input voltage of $40 \mathrm{~V}$. For the direct drive system, the discharge power supply was replaced with a direct connection to the solar array through an EMI filter/matching network. Power for the thermal throttle and cathode heater/ignitor was provided by conventional switching power supplies. It was assumed that these components would weigh on the order of $3 \mathrm{~kg}$ and dissipate $40 \mathrm{~W}$ in steady state operation.

\section{Thermal}

The mass of the thermal rejection system was calculated with the conservative assumption that the specific mass would be 30 $\mathrm{kg} / \mathrm{kW}$. The heat input considered was only from the PPU baseplate. Any heat generated by the thruster was not considered.

\section{DIRECT DRIVE SYSTEM}

The complete elimination of the power processor is not feasible, due to EMI compatibility and thruster ignition requirements. A schematic of the direct drive system appears in Figure 7.

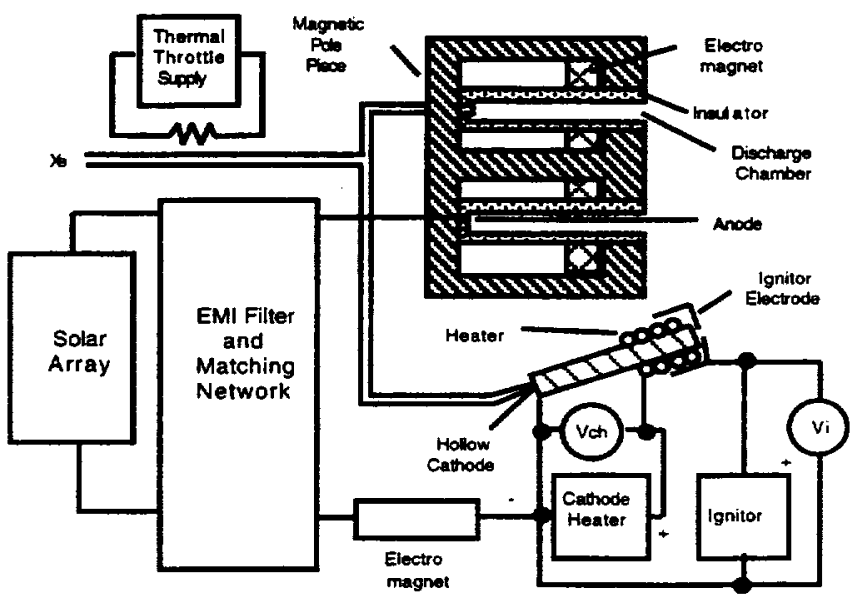

Figure 7. Direct drive SPT system.

Three small power supplies are retained to operate the thermal throttle and provide power to the cathode heater and ignitor. A Controller / Interface Unit must also be included to sequence the power supplies, open propellant valves, and to provide a disconnect between the thruster and solar array in the event of a thruster fault. On/Off control of the thruster can be accomplished by means of removing propellant flow through the thruster.

The EMI Filter and matching network provide appropriate filtering of the thruster current to ensure EMI compatibility with the rest of the spacecraft. The matching network is the last stage of the PPU output filter and is tuned for optimal operation with the thruster. Previously, this filter, described by Hamley, et al. (1993) utilized an LC network with a large DC inductor of approximately $10-15 \mathrm{mH}$ and a $2 \mu \mathrm{F}$ capacitor which was connected between the anode and cathode. A $100 \Omega$ resistor connected across the inductor provided damping. Recent work by Petrenko, et al. (1995) has indicated that these values can be reduced significantly, resulting in a substantial mass reduction of this matching network. However, an additional capacitance may be required for thruster ignition, because a current transient in excess of $15 \mathrm{~A}$ appears at the thruster anode during the ignition process as reported by Hamley, et al. (1993). If the discharge voltage is allowed to fall below $150 \mathrm{~V}$ during ignition, the thruster will operate in a stable mode at low voltage with the current determined by the array characteristics. The additional capacitance would provide sufficient stored charge to prevent the collapse of the array. It is assumed that an additional $2 \mu \mathrm{F}$ of capacitance would be sufficient if the reduced matching network is used. For this analysis, a mass for the EMI 
filter/matching network, the ignition and thermal throttle power supplies, and the controller was estimated at 3 $\mathrm{kg} /$ thruster. Power dissipation was set at $40 \mathrm{~W}$ steady state.

\section{ANALYSIS AND RESULTS}

For the present analysis, a propulsion system consisting of two SPT-100 thrusters was selected with both thrusters operating at the same time in a single string configuration. For the standard propulsion system, it was assumed that each thruster would be driven by a power processor, and that the array and power distribution harness would be configured for a nominal 40 VDC. The direct drive system replaces the discharge power supply of the PPU with a direct connection to a $300 \mathrm{~V}$ solar array and power distribution harness. The results of this analysis are presented in Table I.

Table I. Results of Mass Analysis.

$$
\text { Standard Direct Drive }
$$

$\begin{array}{lrr}\text { Array Mass, kg } & 32.3 & 30.6 \\ \text { Thruster Mass, kg } & 8.0 & 8.0 \\ \text { Power Processor Mass, kg } & 16.5 & 6.0 \\ \text { Thermal Control Mass, kg } & 7.0 & 2.4 \\ \text { Harness Mass, kg } & 7.3 & 1.0 \\ \text { Total Mass, kg } & 71.1 & 48.0 \\ & & \\ \text { Specific Mass, kg/kW } & 26.3 & 17.7 \\ \text { System Power Efficiency } & 0.46 & 0.49\end{array}$

From the table, it is estimated that a total of $23 \mathrm{~kg}$ can be removed from the propulsion system with the elimination of the PPUs. Further improvements in system cost and reliability are realized due to the reduction of the parts count in the PPU and the subsequent reduction in manufacturing costs, especially when the costs of radiation-hardened components is also considered. The significant mass savings can be leveraged in several ways. Additional payload mass can be carried or additional propellant. If a tankage fraction of 0.15 is assumed, $20 \mathrm{~kg}$ of additional xenon can be carried which would result in an additional 1010 hours (505 h/thruster) of operation or an additional $309,000 \mathrm{~N}-\mathrm{s}$ of impulse based on a flow rate of 5.5 $\mathrm{mg} / \mathrm{s}$. Cost savings are realized by the integration of a highly simplified PPU with the spacecraft,

If the specific mass of the system is calculated as the sum of the masses of the power distribution, thermal control system, and the thruster divided by the power delivered to the thruster, the specific mass of the direct drive system is 0.67 that of the standard propulsion system. Further, the system power efficiency is increased to 0.49 from 0.46 . The direct impacts of these savings are strictly spacecraft and mission dependent, and a detailed mission analysis or application is beyond the scope of this effort.

\section{CONCLUSIONS}

PPUs represent a large fraction of the dry mass of electric propulsion systems. Additional system mass results from the need to reject waste heat due to power losses from the PPU. The solar arrays must also provide additional power to compensate for these losses, further increasing the system mass. Solar array output characteristics are suitable for the direct application of power to a Hall thruster if the nominal output of the array can be configured for $300 \mathrm{~V}$ and some simplified power processing and an EMI filter/matching network is provided for cathode ignition and EMI compatibility. Recent data indicate that a state of the art concentrator array can be configured for $300 \mathrm{~V}$ output without concern for arcing in the LEO plasma environment. The direct connection reduces the overall system mass by $23 \mathrm{~kg}$ and improves system power efficiency by three percent. This mass savings can be leveraged by increased payload or propellant and mission life.

\section{REFERENCES}

Bober, A.S., et al., 1991, "State of Work on Electrical Thrusters in the USSR." Proceedings of the 22nd International Electric Propulsion Conference, AIAA Paper 91-003.

Brophy, J.R., et al., 1992 "Performance of the Stationary Plasma Thruster: SPT-100," AIAA Paper 92-3155.

Byers, D.C., 1980, "Upper Stages Utilizing Electric Propulsion," NASA TM-81412.

Day, M., 1995, Personal Communication, Space Systems/Loral, Palo Alto, California.

Fischer, G., et al., 1993, "Design of a High Efficiency Power Processor for the Russian Stationary Plasma Thruster." Proceedings of the 23rd International Electric Propulsion Conference, pp. 396-404.

Gooder, S.T., 1976, "Series-Parallel Method of Direct Solar Array Regulation," NASA TM X-73505.

Gooder, S.T., 1977, "Operational Compatibility od a 30Centimeter Diameter Ion Thruster With Integrally Regulated Solar Array Power Source," NASA TN D-8428.

Gruber, R.P., 1977, "Solar Array Maximum Power Tracking With Closed-Loop Control of a 30-Centimeter Ion Thruster." NASA TM X-73463.

Guidice, D., et al., "Investigation of Space-Environment Effects of Photo-voltaic Technologies by the PASP Plus Experiment," 1995. AIAA Paper 95-0371.

Hamley, J.A., Hill, G.M., and Sankovic, J.M., 1993, "Power Electronics Development for the SPT-100 Thruster," Proceedings of the 23rd International Electric Propulsion Conference, pp. 405-416.

Petrenko, A.N., Hamley, J.A., and Sankovic, J.M., 1995, "The Problem of Power Processor and Telemetry Control Unit Design for the Stationary Plasma Thruster," Proceedings of the 24th International Electric Propulsion Conference. To be Published.

Piszczor, M.F.. O'Neill, M.J., and Fraas. L.M., "Design and Development of a Line-Focus Refractive Concentrator Array For Space," Proceedings of the 29th Intersociety Energy Conversion Engineering Conference, pp. 282-285. 
Sankovic, J.M., Hamley, J.A., and Haag, T.W., 1993. "Performance Evaluation of the Russian SPT-100 Thruster at NASA LeRC,"Proceedings of the 23rd International Electric Propulsion Conference, pp. 855-883, (also NASA TM 106401). 
Public reporting burden for this collection of information is estimated to average 1 hour per response, including the time for reviewing instructions, searching existing dala sources. gathering and mainlaining the data needed, and cormpleting and reviewing the collection of intormation. Send comments regarding this burden estinale or any other aspect of this colection of inlormation, including suggestions for reducing this burden, 10 Washington Headquarters Services. Directorate tor information Operations and Reports, 1215 Jeffer

\begin{tabular}{|l|c|c|}
\hline 1. AGENCY USE ONLY (Leave blank) & $\begin{array}{c}\text { 2. REPORT DATE } \\
\text { May } 1995\end{array}$ & $\begin{array}{r}\text { 3. REPORT TYPE AND DATES COVERED } \\
\text { Technical Memorandum }\end{array}$
\end{tabular}

4. TITLE AND SUBTITLE

Direct Drive Options for Electric Propulsion Systems

6. AUTHOR(S)

John A. Hamley

7. PERFORMING ORGANIZATION NAME(S) AND ADDRESS(ES)

National Aeronautics and Space Administration

Lewis Research Center

Cleveland, Ohio 44135-3191

\section{SPONSORINGMONITORING AGENCY NAME(S) AND ADDRESS(ES)}

National Aeronautics and Space Administration

Washington, D.C. 20546-0001
WU-242-70-02

8. PERForming ORganIZATION REPORT NUMBER

E-9618

10. SPONSORING/MONITORING AGENCY REPORT NUMBER

NASA TM-106576

AIAA-95-364

11. SUPPLEMENTARY NOTES

Prepared for the 30th Intersociety Energy Conversion Engineering Conference cosponsored by ASME, IEEE, AIChE, ANS, ACS, and AIAA, Orlando, Florida, July 31-August 4, 1995. Responsible person, John A. Hamley, organization code 5330, (216) 977-7430.

12a. DISTRIBUTIONAVAILABILITY STATEMENT 12b. DISTRIBUTION CODE

Unclassified - Unlimited

Subject Category 20

This publication is available from the NASA Center for Aerospace Information, (301) 621-0390.

\section{ABSTRACT (Maximum 200 words)}

Power processing units (PPUs) in an electric propulsion system provide many challenging integration issues. The PPU must provide power to the electric thruster while maintaining compatibility with all of the spacecraft power and data systems. Inefficiencies in the power processor produce heat, which must be radiated to the environment in order to ensure reliable operation. Although PPU efficiencies are generally greater than 0.9 , heat loads are often substantial. This heat must be rejected by thermal control systems which generally have specific masses of $15-30 \mathrm{~kg} / \mathrm{kW}$. PPUs also represent a large fraction of the electric propulsion system dry mass. Simplification or elimination of power processing in a propulsion system would reduce the electric propulsion system specific mass and improve the overall reliability and performance. A direct drive system would eliminate all or some of the power supplies required to operate a thruster by directly connecting the various thruster loads to the solar array. The development of concentrator solar arrays has enabled power bus voltages in excess of $300 \mathrm{~V}$ which is high enough for direct drive applications for Hall thrusters such as the Stationary Plasma Thruster (SPT). The option of solar array direct drive for SPTs is explored to provide a comparison between conventional and direct drive system mass.

14. SUBJECT TERMS

Electric propulsion; Power processing; Solar power; Hall thrusters

17. SECURTY CLASSIFICATION OF REPORT

Unclassified
18. SECURITY CLASSIFICATION OF THIS PAGE

Unclassified
19. SECURITY CLASSIFICATION OF ABSTRACT Unclassified 


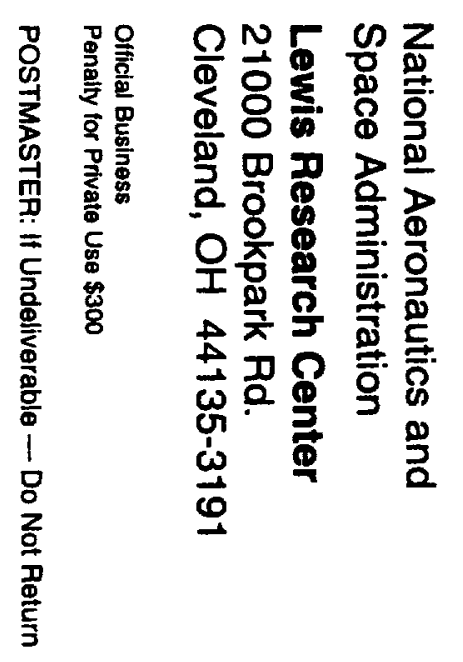

